Proceedings of the 12th International Symposium on Physics of Materials, Prague, September 4-8, 2011

\title{
Activation Energy in Hot Forming of Selected Fe-40at.\%Al Type Intermetallic Compounds
}

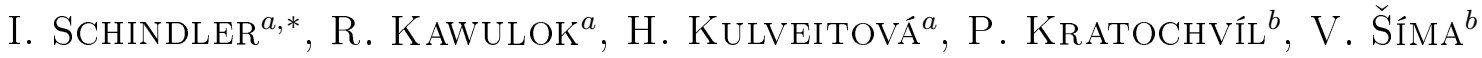 \\ AND M. KNAPIŃSKI ${ }^{c}$ \\ ${ }^{a}$ Faculty of Metallurgy and Materials Engineering, VŠB - Technical University of Ostrava
} 17. listopadu 15, 70833 Ostrava, Czech Republic

${ }^{b}$ Department of Physics of Materials, Charles University in Prague, Ke Karlovu 5, 12116 Prague, Czech Republic ${ }^{c}$ Faculty of Materials Processing Technology and Applied Physics, Częstochowa University of Technology al. Armii Krajowej 19, 42-200 Częstochowa, Poland

Promising potential of the Fe-40at.\%Al type alloys is used only in a limited way as yet, mainly due to their high brittleness. With regard to attraction of the given type material, the plastometric research at temperatures $800{ }^{\circ} \mathrm{C}$ to $1200^{\circ} \mathrm{C}$ was carried out as a basic one, namely using the uniaxial compression tests at strain rates $10^{-2} \mathrm{~s}^{-1}$ to $10^{1} \mathrm{~s}^{-1}$. Cylindrical samples were manufactured from laboratory castings, gained by means of the vacuum induction furnace. Two materials were tested $-\mathrm{Fe}-40 \mathrm{Al}$ and $\mathrm{Fe}-40 \mathrm{Al}+\mathrm{TiB}_{2}$. From the measured flow stress curves the values of maximum stress were obtained and used for determination of the activation energy in hot forming according to the classical equation of the hyperbolic sine type. Enumeration of its parameters led to a possibility to predict maximum deformation resistance values of the investigated alloys in dependence on temperature and strain rate. Pronounced effect of the added titanium diboride particles $(<10 \mu \mathrm{m})$ on the activation energy value and to a resistance to the formation of cracks was observed. Thanks to the obtained value of activation energy an equation sufficiently describing the initiation of dynamic recrystallization process in the $\mathrm{Fe}-40 \mathrm{Al}+\mathrm{TiB}_{2}$ material as a function of the Zener-Hollomon parameter could be derived.

PACS: 81.05.Bx, 81.70.-q, 81.10.Jt

\section{Introduction}

Iron aluminides have been considered as potential candidates for structural applications due to their high temperature oxidation resistance and mechanical properties [1]. The crystal structure of Fe-40at.\%Al intermetallic compounds is of the $B 2$ type. Their properties and comparatively low material costs predestine them for various technical applications, but their promising potential is limited by their considerable brittleness. Conventional techniques of processing of the coarse-grained structure by hot forming, which are accompanied by the repeated recrystallization and progressive grain refining, are feasible only with great difficulty in this case. Issues connected with the low formability can be improved to a certain degree by selected ternary additions, as for instance manganese or boron. Using special protective capsules [2], laboratory castings made of the brittle intermetallic alloys were successfully hot rolled [3,4]. Even the symptoms of superplasticity in the given alloys in conditions of the slow tensile [5] or compression tests [6] are known.

The main goal of the study was to obtain stress-strain curves for two Fe-40at.\% Al type materials of similar composition in a wide range of strain, strain rate and temperature and determine the activation energy during hot

* corresponding author; e-mail: ivo.schindler@vsb.cz forming from the peak stress values. The plastometric tests should enable to determine the effect of added small $\mathrm{TiB}_{2}$ particles $(<10 \mu \mathrm{m})$ on deformation behaviour of the investigated alloys.

\section{Experimental procedures}

Cylindrical samples (diameter of $10 \mathrm{~mm}$, height of $12 \mathrm{~mm}$ ) were manufactured from laboratory castings (cross-section about $20 \mathrm{~mm} \times 33 \mathrm{~mm}$ ) obtained by the vacuum melting in the induction furnace. Table I shows chemical composition of the castings, their very heterogeneous and coarse-grained structure is shown in Fig. 1.

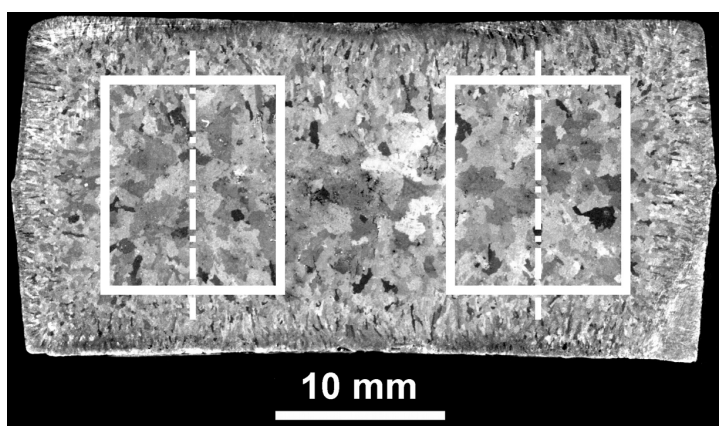

Fig. 1. $\mathrm{FeAl}+\mathrm{TiB}_{2}-$ macrostructure of the casting (cross-section) with indicated positions of two cylindrical samples with diameter of $10 \mathrm{~mm}$ (white colour). 
TABLE I

Chemical composition of the investigated materials in at.\% (balance - Fe).

\begin{tabular}{c|c|c}
\hline \hline & FeAl & FeAl+TiB ${ }_{2}$ \\
\hline $\mathrm{Al}$ & 40.9 & 40.7 \\
$\mathrm{C}$ & 0.05 & 0.15 \\
$\mathrm{Mn}$ & 0.13 & 0.15 \\
$\mathrm{Ti}$ & - & 0.15 \\
$\mathrm{~B}$ & - & 0.27
\end{tabular}

Uniaxial hot compression tests of the cylindrical samples were performed on the dynamic testing machine Gleeble 3800 , after the unified preheating to temperature of $1200^{\circ} \mathrm{C}$. The forming temperatures were 800 , $900,1000,1100$ and $1200^{\circ} \mathrm{C}$, the values of initial strain rate were in the range from $0.05 \mathrm{~s}^{-1}$ to $46 \mathrm{~s}^{-1}$. The formability was favourably influenced by heated swages and so most of the tests could be finished after reaching the true height reduction of about 0.5. The careful analysis of records of variables measured during testing revealed that the setup temperatures were maintained very precisely. Stress-strain curves were calculated from the recorded values of the forming force and compression of the sample. Examples of measured curves are in Fig. 2.

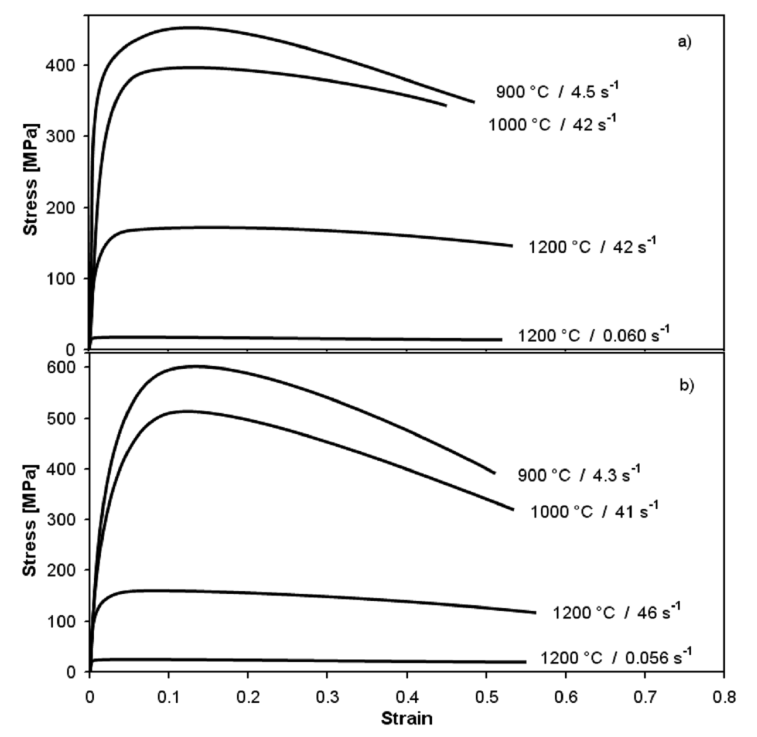

Fig. 2. Comparison of the selected stress-strain curves: (a) FeAl, (b) FeAl+TiB .

\section{Mathematical processing and discussion of results}

The activation energy for hot deformation $Q\left[\mathrm{~J} \mathrm{~mol}^{-1}\right]$ is a parameter dependent on the chemical composition and microstructure of the hot formed material. Knowledge of its value is very useful, e.g. for description of dynamic recrystallization (DRX) kinetics or stress-strain curves at continuous deformation. To determine the value of $Q$ a modified empirical equation often used for hot deformation data [7] was applied

$$
\dot{\varepsilon}=C \exp \left(\frac{-Q}{R T}\right)\left[\sinh \left(\alpha \sigma_{\max }\right)\right]^{n},
$$

where $\dot{\varepsilon}\left[\mathrm{s}^{-1}\right]$ is strain rate; $C\left[\mathrm{~s}^{-1}\right], \alpha\left[\mathrm{MPa}^{-1}\right]$ and $n$ are material parameters; universal gas constant $R=$ $8.314 \mathrm{~J} \mathrm{~mol}^{-1} \mathrm{~K}^{-1} ; T[\mathrm{~K}]$ is deformation temperature; $\sigma_{\max }[\mathrm{MPa}]$ is the maximum (peak) flow stress. This relationship was originally developed for mathematical description of strain rate corresponding to the steady-state stress $\sigma_{\mathrm{ss}}[\mathrm{MPa}]$ and therefore it is basically possible to use both the $\sigma_{\max }$ and $\sigma_{\mathrm{ss}}$ values to evaluate the activation energy. Nevertheless, the peak stress is applied much more frequently because the $\sigma_{\mathrm{ss}}$ values are hardly accessible in wide range of strain rates and temperatures.

The way of assessing the parameters in Eq. (1) was described e.g. in [8]. It can be solved by a graphical method using multiple linear regression analysis. The interactive computing program ENERGY 4.0 [9] enabled more sophisticated processing of the $\left(T ; \dot{\varepsilon} ; \sigma_{\max }\right)$ input data. It starts with a rough estimate of the particular material parameters in Eq. (1) and then the values are repeatedly used in a self-consistent least squares procedure, the result of which is a final model of the dependence $\sigma_{\max }=f(T, \dot{\varepsilon})$. The final regression analysis results for the investigated iron aluminides are summarised in Table II.

TABLE II

Material parameters in Eq. (1).

\begin{tabular}{c|c|c}
\hline \hline Parameter & FeAl & FeAl+TiB 2 \\
\hline$Q\left[\mathrm{~kJ} \mathrm{~mol}^{-1}\right]$ & 240 & 470 \\
$n[-]$ & 2.67 & 2.09 \\
$\alpha\left[\mathrm{MPa}^{-1}\right]$ & 0.0037 & 0.0090 \\
$C\left[\mathrm{~s}^{-1}\right]$ & $3.15 \times 10^{10}$ & $4.81 \times 10^{17}$
\end{tabular}

The obtained values of the activation energy and further material parameters enable this way to predict the maximum deformation resistance of the investigated material in dependence on the temperature-compensated strain rate, defined by the Zener-Hollomon parameter $Z\left[\mathrm{~s}^{-1}\right][10]$ :

$$
\begin{aligned}
& Z=\dot{\varepsilon} \exp \left(\frac{Q}{R T}\right), \\
& \sigma_{\max }=\frac{1}{\alpha} \operatorname{arcsinh}\left(\left(\frac{Z}{C}\right)^{\frac{1}{n}}\right) .
\end{aligned}
$$

A comparison of experimentally measured and according to Eq. (3) calculated $\sigma_{\max }$ values is shown in Fig. 3.

Although the accuracy of plastometric tests was adversely affected by the structural heterogeneity of samples and sometimes also by their premature fracture, the resulting mathematical description of the dependence $\sigma_{\max }=f(T, \dot{\varepsilon})$ may be regarded as sufficiently accurate.

Data dealing with activation energy for hot working or superplastic deformation of iron aluminides-based materials may be found in literature. The problem with the 


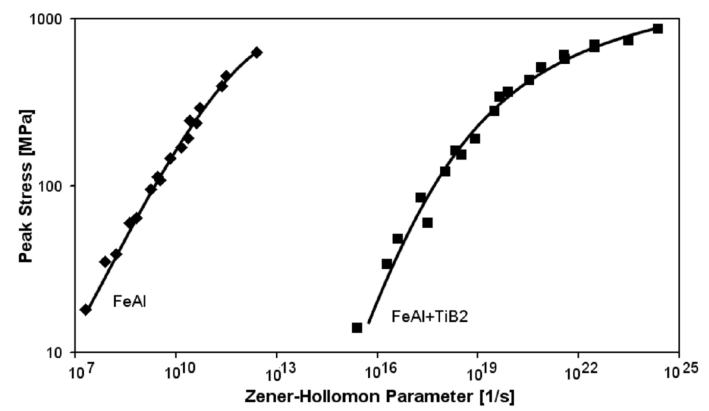

Fig. 3. Comparison of measured $\sigma_{\max }$ values and according to Eq. (3) calculated curves.

comparability of results consists in very different testing conditions (torsion or tensile tests, different orders of strain rates, temperature range, composition and initial microstructure of materials, etc.). Literature data of activation energy for the materials of the FeAl-type (containing of about 40 at. $\% \mathrm{Al}$ ) are summarized in Table III.

TABLE III

Activation energy values of the selected FeAl-type materials.

\begin{tabular}{c|c|c}
\hline \hline Material & $\begin{array}{c}\text { Activation } \\
\text { energy } Q \\
{\left[\mathrm{~kJ} \mathrm{~mol}^{-1}\right]}\end{array}$ & Reference \\
\hline $\begin{array}{c}\text { gas atomized } \\
\text { Fe-39.6Al-0.19Mo-0.05Zr } \\
\text { water atomized }\end{array}$ & 465 & {$[11]$} \\
FeAl Fe-39.4Al-0.18Mo- & 430 & {$[11]$} \\
$0.05 \mathrm{Zr}-0.86 \mathrm{O}_{2}$ & & \\
large-grained Fe-36.5Al & 370 & {$[12]$} \\
large-grained Fe-36.5Al-1Ti & 290 & {$[12]$} \\
large-grained Fe-36.5Al-2Ti & 260 & {$[12]$} \\
Fe-40Al-5Cr-0.2Mo-0.2Zr-0.02B & 343 & {$[13]$}
\end{tabular}

It is obvious that our value $Q=240 \mathrm{~kJ} \mathrm{~mol}^{-1}$ for $\mathrm{Fe}-40 \mathrm{Al}$ alloy is in comparison with values given in Table III quite low, on the other hand it is quite close to the activation energy $\left(265 \mathrm{~kJ} \mathrm{~mol}^{-1}\right)$ for the diffusion of iron in FeAl [14]. The $Q$-values may also be influenced by a methodology for their determination. While we start from the complex hyperbolic sine relation of the type given in Eq. (1), other authors use the equation

$$
\dot{\varepsilon}=A \sigma^{n} \exp \left(\frac{-Q}{R T}\right),
$$

where stress $\sigma[\mathrm{MPa}]$ is on the pertinent stress-strain curve localized differently. It is evident that Eq. (4) corresponds to a simplified shape of Eq. (1) and is suitable for the description of deformation behaviour only at the low stress values $[8,15]$.

From the literature analysis it is obvious that the value of $Q=240 \mathrm{~kJ} \mathrm{~mol}^{-1}$ is closer rather to $Q$-values of some $\mathrm{Fe}_{3} \mathrm{Al}$-based alloys $[11,16]$. However, important is the fact that the addition of $\mathrm{TiB}_{2}$ particles nearly doubled the value of activation energy $Q$ under analogical experimental conditions - see Table II. As follows from comparison of the curves in Fig. 2, this fact leads to a raising of values of deformation resistance characteristics, mainly at lower forming temperatures (below $900^{\circ} \mathrm{C}$ ); at higher temperatures $\left(1100^{\circ} \mathrm{C}\right.$ and more) the deformation resistance characteristics of both examined materials are very similar.

The observed effect of the $\mathrm{TiB}_{2}$ particles addition is most probably due to a partial dissolution of the $\mathrm{TiB}_{2}$ particles during crystallization of the melt and subsequent diffusion of boron into grain boundaries. It is well known that the intergranular segregation of boron is responsible for observed reinforcing effects and improvement of ductility of FeAl-based materials [17].

The strain $\varepsilon_{\mathrm{p}}$ appropriate to the peak stress approximately corresponds to the initiation of the DRX process (see e.g. [18]), resulting at higher strains in steady flow stress value due to a balance between work hardening and continuous dynamic recrystallization which proceeds in overlapping cycles. Sakai and Jonas [19] showed that the overlapping cycles of recrystallization can be observed at high strain rates as a series of "necklaces" of new grains, which are forming at the grain boundaries (see Fig. 4). A correlation between $\varepsilon_{\mathrm{p}}$ and the Zener-Hollomon parameter could be therefore used as a characteristic of the DRX process in the material. In case of the binary FeAl alloy the too flat shapes of stress-strain curves did not enable to determine the $\varepsilon_{\mathrm{p}}$ values with sufficient accuracy.

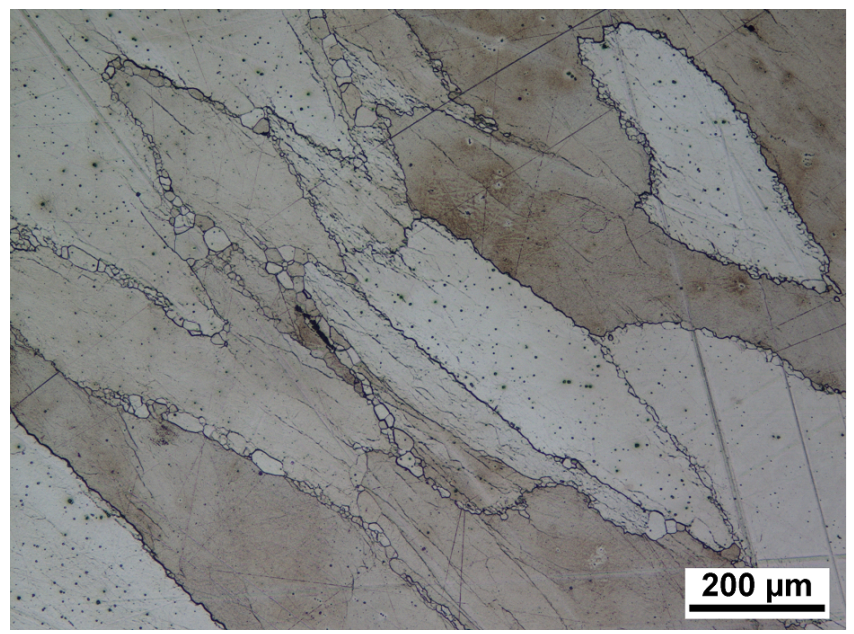

Fig. 4. Microstructure of the FeAl alloy after hot compression: temperature $900^{\circ} \mathrm{C}$, strain rate $0.4 \mathrm{~s}^{-1}$.

On the other hand, in case of the material $\mathrm{FeAl}+\mathrm{TiB}_{2}$ we obtained a relationship between peak strain $\varepsilon_{\mathrm{p}}$ and the Zener-Hollomon parameter in the form

$$
\varepsilon_{\mathrm{p}}=7.0 \times 10^{-4} Z^{0.108} \text {. }
$$

In spite of the complicating effect of internal cavities in the cast material on experimental stress-strain curves, we succeeded in determining basic material parameters describing formability of the investigated materials in conditions of the compression test.

The formability of both materials naturally increases with increasing temperature and with decreasing strain 


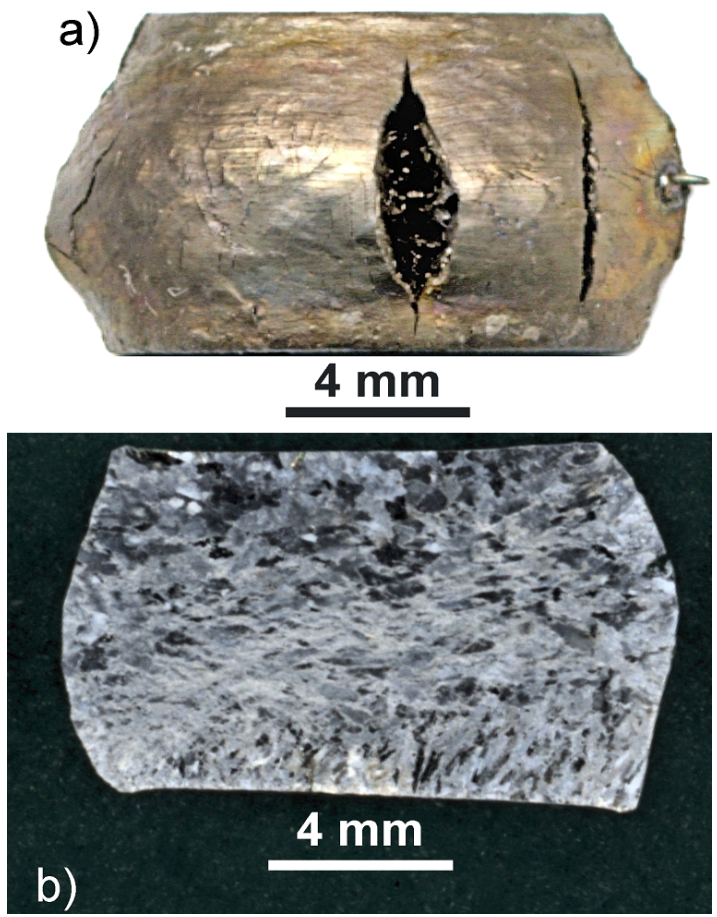

Fig. 5. View of the selected samples after hot compression - $\mathrm{FeAl}+\mathrm{TiB}_{2}$ alloy: (a) temperature $1000^{\circ} \mathrm{C}$, strain rate $41 \mathrm{~s}^{-1}$ — cracks at lateral face surface; (b) temperature $900{ }^{\circ} \mathrm{C}$, strain rate $0.054 \mathrm{~s}^{-1}-$ macrostructure of vertical cross-section.

rate. These trends correspond also with the superplastic behaviour of the iron aluminides at high temperatures and low forming speeds $[5,16]$. An example of cracks at lateral face surface of the compressed sample is shown in Fig. 5. In comparison with binary alloy the material $\mathrm{FeAl}+\mathrm{TiB}_{2}$ showed surprisingly a higher resistance to the formation of cracks. It is probably also due to a strengthening effect of boron atoms dissolved from $\mathrm{TiB}_{2}$ particles during crystallization of the melt.

\section{Summary}

Hot deformation behaviour of two materials (Fe-40Al and $\mathrm{Fe}-40 \mathrm{Al}+\mathrm{TiB}_{2}$ ) was studied by means of the uniaxial compression tests carried out at temperatures from $800^{\circ} \mathrm{C}$ to $1200^{\circ} \mathrm{C}$ and strain rates from $10^{-2} \mathrm{~s}^{-1}$ to $10^{1} \mathrm{~s}^{-1}$. The determined peak flow stress values were used for calculation of the values of activation energy $Q$ in hot forming according to the classical equation of the hyperbolic sine type. The value of $Q=240 \mathrm{~kJ} \mathrm{~mol}^{-1}$ (for $\mathrm{Fe}-40 \mathrm{Al}$ alloy) markedly increased by addition of small $(<10 \mu \mathrm{m}) \mathrm{TiB}_{2}$ particles $\left(Q=470 \mathrm{~kJ} \mathrm{~mol}^{-1}\right.$ for $\mathrm{Fe}-40 \mathrm{Al}+\mathrm{TiB}_{2}$ alloy). Determination of the hyperbolic sine equation parameters enabled to calculate peak stress values, representing maximum deformation resistance of the investigated alloys, in dependence on the temperature-compensated strain rate (i.e. the ZenerHollomon parameter $Z$ ). In case of the $\mathrm{FeAl}+\mathrm{TiB}_{2}$ material the obtained value of activation energy and $\varepsilon_{\mathrm{p}}$ values made possible to characterise the initiation of the DRX process in the material by means of the obtained relation between peak strain $\varepsilon_{\mathrm{p}}$ and the Zener-Hollomon parameter.

\section{Acknowledgments}

This work was carried out in the framework of the project P107/10/0438 (Czech Science Foundation), with utilization of the procedures developed at solving of project No. CZ.1.05/2.1.00/01.0040 (within the frame of the operation programme "Research and Development for Innovations" financed by the Structural Funds and from the state budget of the Czech Republic) and research plan MSM6198910015 (Ministry of Education of the Czech Republic).

\section{References}

[1] S.C. Deevi, V.K. Sikka, Nickel Iron Aluminides 4, 357 (1996).

[2] I. Schindler, M. Šula, Application for the patent $P V$ 2008-301, Czech Patent and Trademark Office, 2008.

[3] I. Schindler, P. Kratochvíl, P. Prokopčáková, P. Kozelský, Intermetallics 18, 745 (2010).

[4] I. Schindler, K. Konečná, H. Kulveitová, J. Kopeček, M. Jarošová, P. Hanus, V. Śíma, M. Cagala, P. Kozelský, M. Legerski, P. Kawulok, S. Rusz, V. Šumšal, Hutnické Listy 63, 26 (2010).

[5] D.L. Lin, D.Q. Li, Y. Liu, Intermetallics 6, 243 (1998).

[6] R. Lyszkowski, J. Bystrzycki, T. Plocinski, Intermetallic 18, 1344 (2010).

[7] C.M. Sellars, W.J. McTegard, Int. Metallurg. Rev. 17, 1 (1972).

[8] C.M. Sellars, W.J. McTegard, Acta Metall. 14, 1136 (1966).

[9] I. Schindler, I. Schindler, J. Plura, M. Heger, J. Bořuta, E. Hadasik, J. Dänemark, in: 12th Int. Conf. Forming 2005, VSB-TUO, Ostrava, 2005, p. 145.

[10] C. Zener, J.H. Hollomon, J. Appl. Phys. 15, 22 (1944).

[11] Y.V.R.K. Prasad, D.H. Sastry, R.S. Sundar, S.C. Deevi, in: 3rd Int. Symp. on Structural Intermetallics, Ed. K.J. Hemker, The Minerals, Metals and Materials Society, Warrendale 2001, p. 233.

[12] D.Q. Li, D.L. Lin, T.L. Lin, Trans. Nonfer. Met. Soc. China 7, 16 (1997).

[13] M. Kupka, Intermetallics 12, 295 (2004).

[14] M. Eggersmann, B. Sepiot, G. Vogl, H. Mehrer, Def. Diff. Forum 339, 143 (1997).

[15] Y.C. Lin, M.S. Chen, J. Zhong, Computat. Mater. Sci. 42, 470 (2008).

[16] D. Lin, L. Lin, A. Shan, M. Chen, Intermetallics 4, 489 (1996).

[17] A. Fraczkiewicz, A.S. Gay, M. Biscondi, Mater. Sci. Eng. A 258, 108 (1998).

[18] C. Rossard, in: Third Int. Conf. on Strength of Metals and Alloys, Vol. II, Institute of Metals and Steel Institute, London 1973, p. 175.

[19] T. Sakai, J.J. Jonas, Acta Mater. 32, 189 (1984). 